\title{
ДИНАМИКА ПОКАЗАТЕЛЕЙ ГЕМОСТАЗА И ЭНДОТЕЛИАЛЬНОЙ ДИСФУНКЦИИ ПРИ ТЕРМИЧЕСКОЙ ТРАВМЕ
}

\author{
В. В. Моррисон ${ }^{1}$, А. Ю. Божедомов²
}

1 Саратовский государственный медицинский университет имени В. И. Разумовского, Саратов, Россия

2 Российский национальный исследовательский медицинский университет имени Н. И. Пирогова, Москва, Россия

Ожоги остаются причиной смертности сотен тысяч людей. Целью работы было изучить динамику изменений показателей системной воспалительной реакции, эндотелиальной дисфункции и нарушений гемостаза у пострадавших от ожогов. У 51 пациента в возрасте 16-80 лет с термическими ожогами

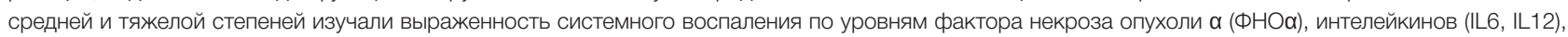
С-реактивного протеина, моноцитарного хемоаттрактантного протеина-1 (МСР-1). Состояние гемостаза оценивали на основании коагулометрических исследований (активированное парциальное тромбопластиновое время (АПТВ), протромбиновый индекс (ПтИ), протромбиновое время (ПТВ) и др.), количества тромбоцитов; дисфункцию эндотелия — по уровням васкулоэндотелиального ростового фактора (VEGF), общего эндотелина (ЭT), циркулирующих эндотелиальных клеток. Показатели изучали в динамике на 1-45-е сутки с момента получения травмы. Наибольшую выраженность

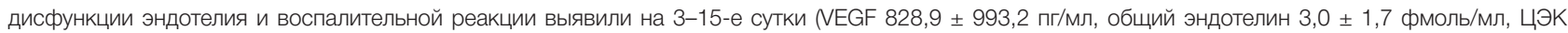

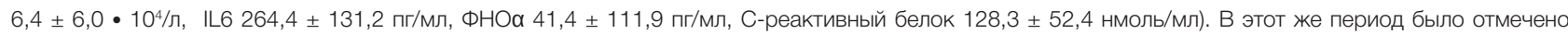
выраженное угнетение коагуляции (АЧТВ 41,4 \pm 17,7 с, ПТИ 83,6 \pm 15,4\%, ПТВ 22,3 \pm 10,0 c). К 30-45-м суткам происходило уменьшение концентрации

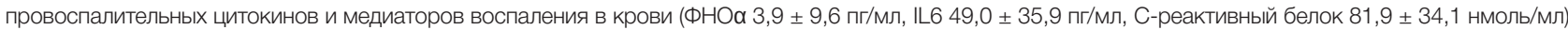

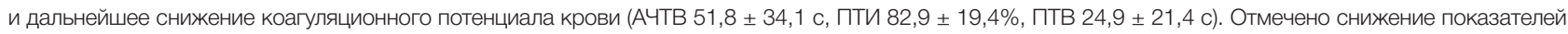
гемокоагуляции. Показано, что происходит повреждение эндотелия сосудов как продуктами, попадающими из ожоговых ран, так и медиаторами воспалительной реакции. Риск тромбоэмболических и геморрагических осложнений максимален с 7-х по 15-е сутки ожоговой болезни. Требуются дальнейшие более детальные исследования механизмов повреждения эндотелия при ожогах.

Ключевые слова: ожоги, эндотелиальная дисфункция, гемостаз, гипокоагуляция, системная воспалительная реакция

Информация о вкладе авторов: Моррисон В. В. - планирование эксперимента, анализ материала, редактирование статьи; Божедомов А. Ю. - сбор и анализ материала, статистическая обработка, написание текста статьи.

Соблюдение этических стандартов: исследование одобрено этическим комитетом Саратовского государственного медицинского университета им. В. И. Разумовского (протокол № 5 от 27 мая 2010 г.); пациенты, включенные в исследование, подписали согласие на публикацию и размещение в интернете информации о характере заболевания, проведенном лечении и его результатах с научной и образовательной целями.

Для корреспонденции: Алексей Юрьевич Божедомов

ул. Островитянова, д. 1, г. Москва, 117997; alecso_84@mail.ru

Статья получена: 28.12.2018 Статья принята к печати: 26.03.2019 Опубликована онлайн: 07.04.2019

DOI: $10.24075 /$ vrgmu.2019.021

\section{DYNAMICS OF HEMOSTASIS PARAMETERS AND ENDOTHELIAL DYSFUNCTION MARKERS IN PATIENTS WITH THERMAL INJURY}

Morrison $\mathrm{W}^{1}$, Bozhedomov AYu ${ }^{2}$

${ }_{1}$ Saratov State Medical University, Saratov, Russia

2 Pirogov Russian National Research Medical University, Moscow, Russia

Burn injuries kill thousands of people. The aim of this study was to investigate the dynamics of systemic inflammatory response parameters, endothelial dysfunction markers and hemostasis impairment in patients with thermal burn injuries. The study was conducted in 51 patients aged 16 to 80 years presenting with moderate to severe thermal burns. The systemic inflammatory response was assessed based on the levels of tumor necrosis factor $\alpha$ (TNFa), a number of interleukins (IL6, IL12), the C-reactive protein, and the monocyte chemoattractant protein 1 (MCP-1). Hemostatic impairments were inferred from the results of coagulation tests that measured the activated partial thromboplastin time (APTT), the prothrombin index (PI), the prothrombin time (PT) and the platelet count. Endothelial dysfunction was analyzed based on the levels of vascular endothelial growth factor (VEGF), total endothelin (TE) and circulating endothelial cells. The dynamics of the listed parameters were studied over 45 days following the injury. Endothelial dysfunction markers peaked on days 3-15 (VEGF $828.9 \pm 993.2 \mathrm{pg} / \mathrm{mL}$, TE $3.0 \pm 1.7 \mathrm{fmol} / \mathrm{mL}$, CEC $6.4 \pm 6.0 \cdot 10^{4} / \mathrm{l}$, IL6 $264.4 \pm 131.2 \mathrm{pg} / \mathrm{mL}$, TNFa $41.4 \pm 111.9 \mathrm{pg} / \mathrm{ml}$, C-reactive protein $\left.128.3 \pm 52.4 \mathrm{nmol} / \mathrm{mL}\right)$. Coagulation was significantly impaired during the same period (APTT $41.4 \pm 17.7 \mathrm{~s}$, PI $83.6 \pm 15.4 \%$, PT $22.3 \pm 10.0 \mathrm{~s}$ ). By day 30-35, blood concentrations of proinflammatory cytokines and inflammation mediators had declined (TNFa $3.9 \pm 9.6 \mathrm{pg} / \mathrm{mL}$, IL6 $49.0 \pm 35.9 \mathrm{pg} / \mathrm{mL}$, C-reactive protein $81.9 \pm 341 \mathrm{nmol} / \mathrm{ml}$ ); in that phase, the coagulation potential was continuing to decrease (APTT $51.8 \pm 34.1 \mathrm{~s}, \mathrm{PI} 82.9 \pm 19.4 \%, \mathrm{PT} 24.9 \pm 21.4 \mathrm{~s}$ ). The study demonstrates that damage to the endothelium results from both injured tissue breakdown and inflammation mediators. The risk of thromboembolic and hemorrhagic complications is the highest on days 7 through 15 following thermal injury. Further research is needed to study the mechanisms of endothelial damage in patients with thermal burns.

Keywords: burns, endothelial dysfunction, hemostasis, hypocoagulation, systemic inflammatory response

Author contribution: Morrison W - design of the experiment, data analysis, manuscript revision; Bozhedomov AYu — data collection and statistical analysis, manuscript draft.

Compliance with ethical standards: the study was approved by the Ethics Committee of Saratov State Medical University (Protocol № 5 dated May 27, 2010); the patients gave informed consent to participate in the study and to disclose information about their medical condition and treatment on the Internet for the sake of science.

Correspondence should be addressed: Alexey Yu. Bozhedomov Ostrovityanova 1, Moscow, 117997; alecso_84@mail.ru

Received: 28.12.2018 Accepted: 26.03.2019 Published online: 07.04.2019

DOI: 10.24075/brsmu.2019.021 
Появляется все больше доказательств сопряжения системного воспаления, гемостаза и эндотелиальной дисфункции при развитии тяжелой патологии [1]. Не является исключением и ожоговая болезнь, возникающая при поражении ожогами более 10\% поверхности тела. Главной причиной смерти пострадавших с ожогами является развитие синдрома полиорганной недостаточности $(\mathrm{C} П \mathrm{OH})$ вследствие срыва механизмов адаптации к травматическому повреждению, истощения энергетических и пластических резервов, а также токсического повреждения органов и тканей продуктами распада тканей из ожоговых ран [2, 3]. Несмотря на достаточную изученность патофизиологических изменений при термических поражениях, ожоги продолжают уносить жизни сотен тысяч людей трудоспособного возраста.

Движущей силой СПОН является феномен, известный под названием «цитокиновый шторм», возникающий вследствие гиперпродукции цитокинов, что ведет $\mathrm{k}$ системному повреждению эндотелия, расстройству микроциркуляции и транскапиллярного обмена [4, 5]. В связи с этим дисфункция эндотелия оказывается одним из важных проявлений и патогенетических звеньев $\mathrm{C} \cap \mathrm{OH}[6]$.

Целью работы было определить динамику изменений показателей гемостаза, системной воспалительной реакции и эндотелиальной дисфункции у пострадавших с термической травмой.

\section{ПАЦИЕНТЫ И МЕТОДЫ}

В проспективное исследование вошли пациенты (51 человек) в возрасте 16-80 лет, находившиеся на лечении в Саратовском центре термических поражений. Средний возраст пациентов составил 40,5 \pm 36,2 лет ( $\mathrm{M} \pm$ б). Среди них было 37 мужчин и 14 женщин. Критерии включения в исследование: наличие термических ожогов (горячей жидкостью или племенем), оцененных по индексу Франка (площадь ожогов I-IIla степени + утроенная площадь ожогов IIIб-IV степени) более чем 30 баллов; значение индекса Франка в среднем - 80,1 \pm 63,2 единиц $(\mathrm{M} \pm \sigma)$. Критерии исключения: возраст пострадавших моложе 16 и старше 80 лет по причине существенного влияния возраста на реактивность организма; наличие электротермического поражения и ожога дыхательных путей, в связи с несоответствием между площадью ожога и общей тяжестью травмы; беременность; наличие декомпенсированных сопутствующих заболеваний на момент поступления. Летальность среди пациентов составила 37\%.

Пациенты были доставлены в стационар в сроки от 1 ч до 3 суток с момента получения термической травмы. На анализаторе StatFax 2100 (Awareness Technology Inc.; США) с помощью количественных иммуноферментных тестов определяли содержание биомаркеров эндотелиальной дисфункции в сыворотке крови, используя наборы реактивов: фактор роста эндотелия сосудов, или VEGF реактивы фирмы Biosource, EuropeS.A (Biosource, EuropeS.A; Бельгия); моноцитарный хемоаттрактантный протеин-1, или МСР-1 - реактивы фирмы «Вектор Бест» («Вектор Бест»; Новосибирск); общий эндотелин реактивы фирмы BiomedicaGruppe (BiomedicaGruppe; Австрия). Исследовали также уровни интерлейкинов IL6 и IL12, фактора некроза опухоли $\alpha$, или $Ф \mathrm{HO \alpha},-$ реактивами фирмы Biosource, EuropeS.A (Biosource, EuropeS.A; Бельгия). Количество циркулирующих эндотелиальных клеток (ЦЭК) определяли по методике J. Hladovec в модификации Н. Н. Петрищева с применением фазово-контрастной микроскопии [7]. Выраженность воспалительной реакции выявляли по уровню С-реактивного белка (СРБ) методом количественного твердофазного иммуноферментного анализа с использованием тест-системы фирмы «ВекторБест» («Вектор-Бест»; Новосибирск). Показатели гемостаза оценивали по уровню фибриногена, протромбиновому времени (ПТВ) и индексу (ПТИ), активированному парциальному тромбопластиновому времени (АПТВ), числу тромбоцитов. Характеристики исследованных факторов эндотелиальной дисфункции представлены в табл. 1.

Кровь отбирали из центральной или периферической вены в 8 ч утра натощак. Анализы проводили на 1-е, 3-и, 7-е, 15-е, 30-е и 45-е сутки с момента получения травмы. Изменение количества пациентов на различных этапах исследования обусловлено как поступлением новых больных в стационар позже чем в первые сутки, так и выбытием из стационара в связи с выпиской или наступлением летального исхода. Все больные получали лечение по стандартам, принятым в клинике.

Контролем служили образцы крови 20 добровольцев без термических повреждений. Из них было 12 мужчин и 8 женщин, средний возраст которых составил 37,5 \pm 18,4 лет. В группу контроля Включали людей без сопутствующей патологии.

\section{Статистика}

Статистическую обработку проводили на персональном компьютере с использованием пакета программ Statistica v10.0 (StatSoft; США). Данные представляли в виде среднего значения и стандартного отклонения ( $\mathrm{M} \pm \sigma)$. Сравнение между группами осуществляли при помощи критерия Стьюдента, который используют при анализе выборок с нормальным распределением. Достоверными считали различия при значениях $p \leq 0,05$, что является стандартом для медико-биологических исследований. Тип распределения определяли при помощи критерия Шапиро-Уилка. При значении $p>0,05$ считали, что выборка имеет нормальное распределение.

Таблица 1. Маркеры эндотелиальной дисфункции

\begin{tabular}{|c|l|}
\hline Название & \multicolumn{1}{|c|}{ Характеристика } \\
\hline VEGF & $\begin{array}{l}\text { Мощный ангиогенный, митогенный фактор; его уровень повышается в ответ на гипоксию различной этиологии, а также при } \\
\text { злокачественных новообразованиях, при регенерации ран, гестозах. Секретируется эндотелиоцитами, макрофагами, } \\
\text { фибробластами и другими клетками [8] }\end{array}$ \\
\hline цЭК & $\begin{array}{l}\text { Уровень повышается при повреждении эндотелия сосудов, при усилении некротических процессов в эндотелии, гипоксии, } \\
\text { сепсисе, тяжелых интоксикациях, атеросклерозе и других сердечно-сосудистых заболеваниях, гестозе [9] }\end{array}$ \\
\hline Эт & $\begin{array}{l}\text { Местный регулятор сосудистого тонуса. Антагонист эндотелиального релаксирующего фактора (NO), косвенный показатель его } \\
\text { активности. Фактор прогрессирования сердечно-сосудистой патологии. Один из факторов патогенеза централизации } \\
\text { кровообращения при дефиците ОЦК. Секретируется эндотелиоцитами [10, 11] }\end{array}$ \\
\hline
\end{tabular}




\section{РЕЗУЛЬТАТЫ}

Показатели коагуляционного гемостаза были достаточно устойчивыми на протяжении всего посттравматического периода. Однако с увеличением времени, прошедшего с момента травмы, было отмечено постепенное снижение ПТИ, удлинение ПТВ и АПТВ, что, вероятнее всего, связано с истощением белковых резервов у данной категории пациентов, а также с проведением активной инфузионной и антитромботической терапии.

Наибольшее повышение уровня фибриногена, являющегося одним из острофазовых белков, наблюдали на 7-е сутки $(5,6 \pm 2,2$ г/л) в период острой ожоговой токсемии.

Динамика изменения содержания тромбоцитов была несколько иной. Их количество наиболее значительно повышалось на 15-30-е сутки (555,3 \pm 344,9 • 10\%/л). При этом отмечено значительное их возрастание у выживших пациентов и отсутствие увеличения у больных с неблагоприятным исходом.

Таким образом, наиболее выраженные изменения гемостаза наблюдали в период острой ожоговой токсемии и септикотоксемии (7-15-е сутки). При этом была отмечена склонность к гиперкоагуляции с повышением вероятности развития тромбоэмболических осложнений (табл. 2).

Анализ динамики изменения уровня провоспалительных цитокинов и медиаторов ответа острой фазы (ФНОа, CPБ, IL6) показал, что их максимальная концентрация наблюдалась на 3-7-е сутки, что соответствовало периоду острой ожоговой токсемии (табл. 3).

В отличие от них уровень IL12, основной точкой приложения которого является стимуляция пролиферации и дифференцировки лимфоцитов, достигал наибольших значений в период реконвалесценции (131,3 \pm 70,7 пг/мл), а в период острой ожоговой токсемии и септикотоксемии имел минимальные значения (35,7 \pm 22,9 пг/мл).

Уровень моноцитарного хемоаттрактантного протеина-1, хемокина, который выделяется различными клетками, в первую очередь фибробластами, эндотелиальными клетками и макросрагами, и привлекает в очаг воспаления моноциты, имел два пика повышения: первый - в период острой ожоговой токсемии (381,7 $\pm 560,49$ пг/мл), второй более выраженный — в период реконвалесценции $(514,7 \pm$ 740,9 пг/мл)

При изучении динамики уровня маркеров дисфункции эндотелия было отмечено, что наибольшей концентрации он достигает на 3-7-е сутки. Так на 7-е сутки уровень VEGF возрос почти в 30 раз по сравнению с контролем $(828,9 \pm$ 993,2 пг/мл). В эти сроки установлено статистически значимое повышение количества десквамированных эндотелиоцитов в плазме крови до 5,9 \pm 6,0 • 10\% (табл. 4). Это свидетельствует об остром гипоксическом поражении эндотелия, его усиленном слущивании, усилении процессов апоптоза и некроза.

Для выявления факторов, наиболее значимо отличающихся при нарушениях в системе гемостаза, было проведено сравнение концентрации цитокинов и маркеров эндотелиальной дисфункции при гипо- и нормокоагуляционных состояниях у пострадавших с ожогами. Наличие гипокоагуляции диагностировали при удлинении АПТВ более 35 с, снижении ПТИ менее 85\% (табл. 5, 6). Установлено, что гипокоагуляции сопутствовали значительно повышенные уровни острофразовых показателей

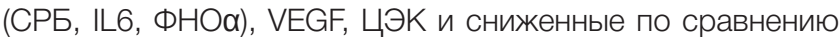
с группой нормокоагуляции значения IL 12, MCP-1, эндотелина.

Таблица 2. Динамика показателей гемостаза у пострадавших с ожогами, $\mathrm{M} \pm \sigma$

\begin{tabular}{|c|c|c|c|c|c|c|c|}
\hline Показатель & $\begin{array}{c}1 \text {-е сутки } \\
n=50\end{array}$ & $\begin{array}{c}\text { 3-и сутки } \\
n=51\end{array}$ & $\begin{array}{c}\text { 7-е сутки } \\
n=49\end{array}$ & $\begin{array}{c}15-е \text { сутки } \\
n=40\end{array}$ & $\begin{array}{c}\text { 30-е сутки } \\
n=36\end{array}$ & $\begin{array}{c}45-е \text { сутки } \\
n=19\end{array}$ & $\begin{array}{c}\text { Контроль } \\
n=20\end{array}$ \\
\hline АЧТВ, C & $\begin{array}{l}39,6 \pm 25,4 \\
\left(p_{\kappa}=0,02\right)^{\kappa}\end{array}$ & $\begin{array}{c}41,4 \pm 17,7 \\
\left(p=0,5, p_{\kappa}=0,05\right)\end{array}$ & $\begin{array}{c}41,9 \pm 25,3 \\
\left(p=0,88, p_{\mathrm{k}}=0,03\right)^{\mathrm{k}}\end{array}$ & $\begin{array}{c}40,2 \pm 27,0 \\
\left(p=0,48, p_{\mathrm{k}}=0,27\right)\end{array}$ & $\begin{array}{c}50,4 \pm 31,4 \\
\left(p=0,001, p_{\mathrm{\kappa}}=0,03\right)^{\star \kappa}\end{array}$ & $\begin{array}{c}51,8 \pm 34,1 \\
\left(p=0,80, p_{\mathrm{K}}=0,04\right)^{\mathrm{K}}\end{array}$ & $26,2 \pm 2,8$ \\
\hline пти, \% & $\begin{array}{l}90,9 \pm 14,1 \\
\left(p_{\mathrm{K}}=0,25\right)\end{array}$ & $\begin{array}{c}86,5 \pm 13,3 \\
\left(p=0,03, p_{\mathrm{K}}=0,02\right)^{*_{\mathrm{K}}}\end{array}$ & $\begin{array}{c}83,6 \pm 15,4 \\
\left(p=0,09, p_{\mathrm{K}}=0,01\right)^{\mathrm{k}}\end{array}$ & $\begin{array}{c}83,1 \pm 16,5 \\
\left(p=0,86, p_{\mathrm{k}}=0,01\right)^{\mathrm{k}}\end{array}$ & $\begin{array}{c}82,3 \pm 17,5 \\
\left(p=0,07, p_{\mathrm{k}}=0,01\right)^{\mathrm{k}}\end{array}$ & $\begin{array}{c}82,9 \pm 19,4 \\
\left(p=0,82, p_{\kappa}=0,03\right)^{\kappa}\end{array}$ & $101,1 \pm 6,3$ \\
\hline ПТВ, с & $\begin{array}{l}19,5 \pm 6,3 \\
\left(p_{\mathrm{k}}=0,04\right)^{\mathrm{k}}\end{array}$ & $\begin{array}{c}22,2 \pm 17,6 \\
\left(p=0,22, p_{\mathrm{k}}=0,04\right)^{\mathrm{k}}\end{array}$ & $\begin{array}{c}22,3 \pm 10,0 \\
\left.p=0,82, p_{\mathrm{k}}=0,03\right)\end{array}$ & $\begin{array}{c}21,8 \pm 8,0 \\
\left(p=0,96, p_{\kappa}=0,01\right)^{\kappa}\end{array}$ & $\begin{array}{c}24,9 \pm 21,4 \\
\left(p=0,11, p_{\mathrm{k}}=0,04\right)^{\mathrm{k}}\end{array}$ & $\begin{array}{c}22,9 \pm 13,5 \\
\left(p=0,52, p_{\kappa}=0,04\right)^{\mathrm{k}}\end{array}$ & $12,6 \pm 0,9$ \\
\hline $\begin{array}{l}\text { Фибриноген, } \\
\text { г/л }\end{array}$ & $\begin{array}{c}3,4 \pm 1,4 \\
\left(p_{\mathrm{K}}=0,11\right)\end{array}$ & $\begin{array}{c}5,2 \pm 2,0 \\
\left(p=0,001, p_{\mathrm{k}}=0,04\right)^{\star_{\mathrm{K}}}\end{array}$ & $\begin{array}{c}5,6 \pm 2,2 \\
\left(p=0,43, p_{\mathrm{k}}=0,001\right)^{\mathrm{k}}\end{array}$ & $\begin{array}{c}5,0 \pm 2,1 \\
\left(p=0,06, p_{\mathrm{k}}=0,001\right)^{\mathrm{k}}\end{array}$ & $\begin{array}{c}4,7 \pm 1,8 \\
\left(p=0,22, p_{\mathrm{\kappa}}=0,001\right)^{\mathrm{\kappa}}\end{array}$ & $\begin{array}{c}4,2 \pm 1,7 \\
\left(p=0,03, p_{\mathrm{k}}=0,05\right)\end{array}$ & $3,3 \pm 0,69$ \\
\hline $\begin{array}{l}\text { Тромбоциты, } \\
\bullet 10^{9} / л\end{array}$ & $\begin{array}{c}319,6 \pm 197,0 \\
\left(p_{\mathrm{k}}=0,27\right)\end{array}$ & $\begin{array}{c}209 \pm 122,9 \\
\left(p=0,001, p_{\mathrm{k}}=0,47\right)^{\star}\end{array}$ & $\begin{array}{c}316,0 \pm 214,6 \\
\left(p=0,001, p_{\kappa}=0,09\right)^{\star}\end{array}$ & $\begin{array}{c}555,3 \pm 344,9 \\
\left(p=0,001, p_{\kappa}=0,04\right)^{*_{K}}\end{array}$ & $\begin{array}{c}467,8 \pm 237,9 \\
\left(p=0,04, p_{\kappa}=0,03\right)^{\star_{\kappa}}\end{array}$ & $\begin{array}{c}454,3 \pm 294,4 \\
\left(p=0,03, p_{\kappa}=0,03\right)^{\kappa}\end{array}$ & $230,4 \pm 224,9$ \\
\hline
\end{tabular}

Примечание: $p$ - при сравнении данного и предыдущего этапов исследования; * - разница достоверна по сравнению с предыдущим этапом исследования ( $p<0,05) ; p_{\kappa}$ — при сравнении результатов на данном этапе с контрольной группой; ${ }^{\text {к }}$ - разница достоверна по сравнению с контрольной группой $(p<0,05)$

Таблица 3. Динамика уровней цитокинов у пострадавших с ожогами, $\mathrm{M} \pm \sigma$

\begin{tabular}{|c|c|c|c|c|c|c|c|}
\hline Показатель & $\begin{array}{c}\text { 1-е сутки } \\
n=50\end{array}$ & $\begin{array}{c}\text { 3-и сутки } \\
n=51\end{array}$ & $\begin{array}{c}\text { 7-е сутки } \\
n=49\end{array}$ & $\begin{array}{c}15-е \text { сутки } \\
n=40\end{array}$ & $\begin{array}{c}\text { 30-е сутки } \\
n=36\end{array}$ & $\begin{array}{c}\text { 45-е сутки } \\
n=19\end{array}$ & $\begin{array}{c}\text { Контроль } \\
n=20\end{array}$ \\
\hline ФНОа, пг/мл & $\begin{array}{l}42,3 \pm 46,6 \\
\left(p_{\mathrm{k}}=0,04\right)^{\mathrm{k}}\end{array}$ & $\begin{array}{c}32,2 \pm 99,3 \\
\left(p=0,79, p_{\mathrm{k}}=0,03\right)^{\mathrm{k}}\end{array}$ & $\begin{array}{c}41,4 \pm 111,9 \\
\left(p=0,85, p_{\mathrm{k}}=0,02\right)^{\mathrm{k}}\end{array}$ & $\begin{array}{c}17,8 \pm 47,9 \\
\left(p=0,45, p_{\mathrm{\kappa}}=0,03\right)^{\mathrm{\kappa}}\end{array}$ & $\begin{array}{c}3,9 \pm 9,6 \\
\left(p=0,26, p_{\mathrm{k}}=0,003\right)^{\mathrm{k}}\end{array}$ & $\begin{array}{c}8,2 \pm 12,1 \\
\left(p=0,30, p_{\mathrm{K}}=0,01\right)^{\mathrm{K}}\end{array}$ & $0,2 \pm 0,3$ \\
\hline IL6, пг/мл & $\begin{array}{c}114,1 \pm 172,8 \\
\left(p_{\mathrm{k}}=0,008\right)^{\mathrm{k}}\end{array}$ & $\begin{array}{c}264,4 \pm 131,2 \\
\left(p=0,05, p_{\mathrm{K}}=0,001\right)^{\mathrm{k}}\end{array}$ & $\begin{array}{c}203,8 \pm 180,9 \\
\left(p=0,39, p_{\mathrm{K}}=0,001\right)^{\mathrm{K}}\end{array}$ & $\begin{array}{c}67,8 \pm 63,4 \\
\left(p=0,07, p_{\mathrm{k}}=0,001\right)^{\mathrm{k}}\end{array}$ & $\begin{array}{c}49,0 \pm 35,9 \\
\left(p=0,51, \mathrm{p}_{\mathrm{k}}=0,001\right)^{\mathrm{k}}\end{array}$ & $\begin{array}{c}68,9 \pm 66,3 \\
\left(p=0,51, p_{\mathrm{K}}=0,001\right)^{\mathrm{K}}\end{array}$ & $4,2 \pm 3,1$ \\
\hline IL12, пг/мл & $\begin{array}{l}46,9 \pm 53,8 \\
\left(p_{\mathrm{k}}=0,001\right)^{\mathrm{K}}\end{array}$ & $\begin{array}{c}39,4 \pm 32,9 \\
\left(p=0,63, p_{\mathrm{k}}=0,001\right)^{\mathrm{k}}\end{array}$ & $\begin{array}{c}35,7 \pm 22,9 \\
\left(p=0,45, p_{\mathrm{\kappa}}=0,001\right)^{\mathrm{k}}\end{array}$ & $\begin{array}{c}54,9 \pm 41,0 \\
\left(p=0,03, p_{\mathrm{K}}=0,001\right)^{* \mathrm{~K}}\end{array}$ & $\begin{array}{c}81,3 \pm 50,0 \\
\left(p=0,06, \mathrm{p}_{\mathrm{k}}=0,001\right)^{\mathrm{k}}\end{array}$ & $\begin{array}{c}131,3 \pm 70,7 \\
\left(p=0,02, p_{\mathrm{k}}=0,001\right)^{\kappa \star}\end{array}$ & $3,1 \pm 3,2$ \\
\hline $\begin{array}{c}\text { С-реактивный белок, } \\
\text { нмоль/мл }\end{array}$ & $\begin{array}{l}43,2 \pm 46,6 \\
\left(p_{\mathrm{k}}=0,001\right)^{\mathrm{K}}\end{array}$ & $\begin{array}{c}128,1 \pm 49,6 \\
\left(p=0,001, p_{\mathrm{K}}=0,001\right)^{* \mathrm{~K}}\end{array}$ & $\begin{array}{c}128,3 \pm 52,4 \\
\left(p=0,93, p_{\mathrm{K}}=0,001\right)^{\mathrm{K}}\end{array}$ & $\begin{array}{c}85,1 \pm 41,7 \\
\left(p=0,001, p_{\mathrm{K}}=0,001\right)^{\star \mathrm{\kappa}}\end{array}$ & $\begin{array}{c}81,9 \pm 34,1 \\
\left(p=0,79, p_{\mathrm{K}}=0,001\right)^{\mathrm{K}}\end{array}$ & $\begin{array}{c}110,3 \pm 57,7 \\
\left(p=0,08, p_{\mathrm{K}}=0,001\right)^{\mathrm{K}}\end{array}$ & $1,2 \pm 1,1$ \\
\hline МСР-1, пг/мл & $\begin{array}{c}198,9 \pm 191,7 \\
\left(p_{\mathrm{k}}=0,001\right)^{\mathrm{k}}\end{array}$ & $\begin{array}{c}319,1 \pm 238,3 \\
\left(p=0,04, p_{\mathrm{K}}=0,001\right)^{\star \kappa}\end{array}$ & $\begin{array}{c}381,7 \pm 560,49 \\
\left(p=0,5, p_{\mathrm{K}}=0,009\right)^{\mathrm{K}}\end{array}$ & $\begin{array}{c}229,9 \pm 210,3 \\
\left(p=0,11, p_{\mathrm{K}}=0,001\right)^{\mathrm{K}}\end{array}$ & $\begin{array}{c}287,1 \pm 231,9 \\
\left(p=0,29, p_{\mathrm{K}}=0,001\right)^{\mathrm{K}}\end{array}$ & $\begin{array}{c}514,7 \pm 740,9 \\
\left(p=0,11, p_{\kappa}=0,009\right)^{\kappa}\end{array}$ & $44,1 \pm 36,5$ \\
\hline
\end{tabular}

Примечание: $p$ — при сравнении данного и предыдущего этапов исследования; * - разница достоверна $(p<0,05)$ по сравнению с предыдущим этапом исследования; $p_{к}$ — при сравнении результатов на данном этапе с контрольной группой; ${ }^{k}-$ разница достоверна $(p<0,05)$ при сравнении с контрольной группой. 


\section{ОБСУЖДЕНИЕ РЕЗУЛЬТАТОВ}

При анализе полученных данных видно, что высокий уровень провоспалительных цитокинов сочетается с нарушением коагуляционного потенциала, повышением содержания маркеров дисфункции эндотелия. Проведенные нами ранее исследования уровня цитокинов при разной степени тяжести термических ожогов свидетельствуют о том, что при ожогах имеют место фазовые изменения уровня маркеров эндотелиальной дисфункции. Так, при легких и умеренных ожогах имеет место значительный рост показателей, при тяжелых, но не фатальных поражениях, они достигают максимальных цифр, однако при фатальных поражениях и терминальной стадии СПОН наблюдается их снижение [12]. Известно, что эндотелиальная дисфункция служит пусковым механизмом для активации как тромбоцитарного, так и коагуляционного механизмов свертывания крови и развития ДВС-синдрома. Нарушение целостности сосудистой стенки приводит К гиперпродукции эндотелина, являющегося стимулятором активации всех фаз системы гемостаза, его уровень повышается при тяжелых травматических повреждениях [13, 14].

На основании этих данных можно сделать вывод, что уровни провоспалительных цитокинов и факторов эндотелиальной дисфункции при тяжелых ожогах находятся в обратно пропорциональной зависимости.

Цитокины усиливают продукцию фрагоцитами, цитотоксическими лимфоцитами факторов, повреждающих эндотелий, таких как свободные радикалы, лизосомные ферменты, катионные белки, активируют гуморальные факторы (комплемент, пропердин, кинины), и тем самым вызывают развитие дисфункции эндотелия. Эндотелиоциты в ответ на это активируют продукцию регуляторных факторов, действующих ауто- и паракринно, например VEGF и эндотелина. При активации провоспалительными цитокинами эндотелиоциты увеличивают экспрессию молекул адгезии, вызывают дегрануляцию телец ВайбеляПаладе (везикулы в клетках сосудистого эндотелия), что приводит к дестабилизации эндотелиальной выстилки, снижению тромборезистентности и повышению сосудистой проницаемости [15]. Увеличение количества десквамированных эндотелиоцитов является результатом повреждения эндотелия сосудов. Повышение концентрации VEGF направлено на регулирование процессов неоангиогенеза в ответ на гипоксическое повреждение эндотелия в период ожоговой токсемии, и на активацию регенерации тканей в период реконвалесценции (на 30-45-е сутки) [13]. Наиболее вероятно, что значительно изменяется функция индуцибельной NO-синтазы, так как имеются данные о снижении при термической травме в крови уровней метаболитов NO [16]. В связи с этим нарастание в крови уровня эндотелина может быть компенсаторным. Есть данные об участии данного фактора в патогенезе централизации кровообращения при других критических состояниях [10].

При увеличении концентраций повреждающих факторов отмечаются нарушение функции эндотелия, развитие энергодесицита, нарушение синтеза белка и как результат - угнетение его прокоагулянтных свойств и развитие гипокоагуляции. Отмечается снижение уровня плазменных факторов свертывания крови вследствие развития ДВС-синдрома, развивающегося у большинства пациентов с тяжелыми ожогами. Кроме этого, часто возникает дефицит пластического материала, в первую очередь аминокислот, большая часть которых расходуется на регенераторные процессы в ожоговых ранах.

\section{ВЫВОДЫ}

Полученные данные свидетельствуют, что при термической травме происходит повреждение структурно-функциональной

Таблица 4. Динамика маркеров эндотелиальной дисфункции у пострадавших с ожогами, $\mathrm{M} \pm \sigma$

\begin{tabular}{|c|c|c|c|c|c|c|c|}
\hline Показатель & $\begin{array}{c}\text { 1-е сутки } \\
n=50\end{array}$ & $\begin{array}{c}\text { 3-и сутки } \\
n=51\end{array}$ & $\begin{array}{c}\text { 7-е сутки } \\
n=49\end{array}$ & $\begin{array}{c}\text { 15-е сутки } \\
n=40\end{array}$ & $\begin{array}{c}\text { 30-е сутки } \\
n=36\end{array}$ & $\begin{array}{c}\text { 45-е сутки } \\
\quad n=19\end{array}$ & $\begin{array}{c}\text { Контроль } \\
n=20\end{array}$ \\
\hline VEGF,пг/мл & $\begin{array}{c}546,4 \pm 692,8 \\
\left(p_{k}=0,02\right)^{k}\end{array}$ & $\begin{array}{c}476,4 \pm 626,9 \\
\left(p=0,68, p_{\mathrm{K}}=0,003\right)^{\mathrm{K}}\end{array}$ & $\begin{array}{c}828,9 \pm 993,2 \\
\left(p=0,06, p_{\mathrm{k}}=0,001\right)^{\mathrm{k}}\end{array}$ & $\begin{array}{c}544,4 \pm 570,9 \\
\left(p=0,11, p_{\mathrm{K}}=0,001\right)^{\mathrm{\kappa}}\end{array}$ & $\begin{array}{c}505,6 \pm 551,1 \\
\left(p=0,77, p_{\mathrm{K}}=0,001\right)^{\mathrm{k}}\end{array}$ & $\begin{array}{c}958,1 \pm 1025,6 \\
\left(p=0,04, p_{\kappa}=0,001\right)^{\star_{\kappa}}\end{array}$ & $28,7 \pm 15,7$ \\
\hline $\begin{array}{l}\text { Эндотелин, } \\
\text { фмоль/мл }\end{array}$ & $\begin{array}{c}3,2 \pm 3,2 \\
\left(p_{\mathrm{k}}=0,001\right)^{\mathrm{k}}\end{array}$ & $\begin{array}{c}3,0 \pm 1,7 \\
\left(p=0,88, p_{\mathrm{K}}=0,001\right)^{\mathrm{K}}\end{array}$ & $\begin{array}{c}2,97 \pm 1,32 \\
\left(p=0,76, p_{\mathrm{k}}=0,001\right)^{\mathrm{k}}\end{array}$ & $\begin{array}{c}2,4 \pm 1,2 \\
\left(p=0,11, p_{\mathrm{\kappa}}=0,001\right)^{\mathrm{K}}\end{array}$ & $\begin{array}{c}2,3 \pm 1,1 \\
\left(p=0,71, p_{\kappa}=0,001\right)^{\mathrm{K}}\end{array}$ & $\begin{array}{c}2,4 \pm 1,3 \\
\left(p=0,93, p_{\mathrm{K}}=0,001\right)^{\mathrm{K}}\end{array}$ & $0,42 \pm 0,4$ \\
\hline ЦЭК, 104/л & $\begin{array}{c}3,3 \pm 2,5 \\
\left(p_{\mathrm{k}}=0,48\right)\end{array}$ & $\begin{array}{c}4,7 \pm 3,3 \\
\left(p=0,09, p_{\mathrm{k}}=0,05\right)\end{array}$ & $\begin{array}{c}5,9 \pm 4,9 \\
\left(p=0,28, p_{\kappa}=0,03\right)^{\kappa}\end{array}$ & $\begin{array}{c}6,4 \pm 6,0 \\
\left(p=0,62, p_{k}=0,04\right)^{\mathrm{k}}\end{array}$ & $\begin{array}{c}3,7 \pm 3,1 \\
\left(p=0,02, p_{\kappa}=0,29\right)^{\star}\end{array}$ & $\begin{array}{c}2,9 \pm 1,6 \\
\left(p=0,33, p_{\mathrm{k}}=0,78\right)\end{array}$ & $2,8 \pm 1,9$ \\
\hline
\end{tabular}

Примечание: $p$ - при сравнении между данным и предыдущим этапом исследования; * - разница достоверна (p < 0,05) по сравнению с предыдущим этапом исследования; $p_{\kappa}$ — при сравнении результатов на данном этапе с контрольной группой; ${ }^{\kappa}-$ разница достоверна (p < 0,05) при сравнении с контрольной группой.

Таблица 5. Различие показателей свертывающей системы крови при нормо- и гипокоагуляции у пострадавших с ожогами, $\mathrm{M} \pm \sigma$

\begin{tabular}{|c|c|c|c|c|c|}
\hline Группа & АЧТВ, с & ПТВ, с & ПТИ, \% & Фибриноген, г/л & Тромбоциты, •109/л \\
\hline Нормокоагуляция & $31,3 \pm 2,9$ & $19,0 \pm 3,6$ & $89,1 \pm 13,4$ & $4,2 \pm 1,2$ \\
\hline Гипокоагуляция & $54,5 \pm 27,9(p=0,001)^{\star}$ & $20,9 \pm 5,0(p=0,01)^{\star}$ & $81,8 \pm 12,8(p=0,001)^{\star}$ & $4,9 \pm 1,4(p=0,001)^{\star}$ & $391,2 \pm 216,9(p=0,99)$ \\
\hline
\end{tabular}

Примечание: * - разница достоверна по сравнению с соответствующим показателем группы нормокоагуляции (p < 0,05).

Таблица 6. Различие показателей цитокинов и маркеров эндотелиальной дисфункции при нормо- и гипокоагуляции у больных с ожогами, М \pm б

\begin{tabular}{|c|c|c|c|c|c|c|c|c|}
\hline Группа & $\begin{array}{c}\text { СРБ, } \\
\text { нмоль/мл }\end{array}$ & IL6, пг/мл & ФНО, пг/мл & IL12, пг/мл & МСР-1, пг/мл & VEGF, пг/мл & ЕT, фмоль/мл & ЦЭК, • 104/ת \\
\hline Нормо-коагуляция & $75,0 \pm 49,1$ & $50,3 \pm 63,9$ & $9,1 \pm 28,5$ & $68,6 \pm 55,6$ & $308,2 \pm 231,6$ & $578,5 \pm 523,9$ & $2,96 \pm 2,7$ & $4,4 \pm 3,6$ \\
\hline Гипо-коагуляция & $\begin{array}{c}97,4 \pm 47,7 \\
(p=0,04)^{*}\end{array}$ & $\begin{array}{c}145,2 \pm 138,3 \\
(p=0,35)\end{array}$ & $\begin{array}{c}45,5 \pm 114,3 \\
(p=0,10)\end{array}$ & $\begin{array}{c}48,3 \pm 46,4 \\
(p=0,08)\end{array}$ & $\begin{array}{c}252,8 \pm 238,2 \\
(p=0,26)\end{array}$ & $\begin{array}{c}712,3 \pm 745,0 \\
(p=0,35)\end{array}$ & $\begin{array}{l}2,41 \pm 1,3 \\
(p=0,21)\end{array}$ & $\begin{array}{l}5,0 \pm 4,9 \\
(p=0,37)\end{array}$ \\
\hline
\end{tabular}

Примечание: * - разница достоверна по сравнению с соответствующим показателем группы нормокоагуляции $(p<0,05)$. 
организации эндотелия сосудов, являющееся отражением системной воспалительной реакции с появлением в крови высокоспецифичных маркеров эндотелиальной дисфункции. При тяжелых ожогах отмечается обратно пропорциональная связь между уровнем провоспалительных цитокинов и функциональными показателями системы гемостаза, что следует учитывать при лечении данной патологии. Необходимы дальнейшие, более глубокие исследования зависимости между эндотелиальной дисфункцией и нарушениями гемостаза при критических состояниях в целом и при тяжелых ожогах в частности.

\section{Литература}

1. Dumnicka P, Maduzia D, Ceranowicz P, et al. The Interplay between Inflammation, Coagulation and Endothelial Injury in the Early Phase of Acute Pancreatitis: Clinical Implications. Int J Mo Sci. 2017; 18 (2): E354. DOI: 10.3390/ijms18020354. PubMed PMID: 28208708.

2. Алексеев А. А., Ушакова Т. А., Крутиков М. Г., Бобровников А. Э. Маркеры сепсиса в диагностике адаптивного воспаления при ожоговой травме. Лечение и профилактика. 2015; 2 (14): 84-91.

3. Ушакова Т. А. Адаптация к ожоговой травме: проблемь и перспективы. Комбустиология. 2009; 39. Доступно по ссылке: www.combustiolog.ru (дата обращения 23.06.2018).

4. Chousterman BG, Swirski FK, Weber GF. Cytokine storm and sepsis disease pathogenesis. Semin Immunopathol. 2017; 39 (5): $517-28$.

5. Ince C, Mayeux PR, Nguyen T, et al. The endothelium in sepsis. Shock. 2016; 45 (3): 259-70.

6. Abdel-Hafez NM, Saleh Hassan Y, El-Metwally TH. A study on biomarkers, cytokines, and growth factors in children with burn injuries. Ann Burns Fire Disasters. 2007; 20 (2): 89-100.

7. Петрищев Н. Н., Беркович О. А., Власов Т. Д. и др. Диагностическая ценность определения десквамированных эндотелиальных клеток в крови. Клиническая лабораторная диагностика. 2001; (1): 50-2.

8. Гавриленко Т. И., Рыжкова Н. А., Пархоменко А. Н. Сосудистый эндотелиальный фактор роста в клинике внутренних заболеваний и его патогенетическое значение. Український кардіологічний журнал. 2011; (4): 87-95.

9. Erdbruegger U, Haubitez M, Woywodt A. Circulating endothelia cells: a novel marker of endothelial damage. Clinica Chimica Acta. 2006; (373): 17-26.

10. Дремина Н. Н, Шурыгин М. Г., Шурыгина И. А. Эндотелины в норме и патологии. Международный журнал прикладных и фундаментальных исследований. 2016; (10): 210-14.

11. Yanagisawa M, Masaki T. Molecular biology and biochemistry of the endothelins. Trends Pharmacol Sci. 1989; 10 (9): 374-8.

12. Моррисон В. В., Божедомов А. Ю. Дисфункция эндотелия при синдроме полиорганной недостаточности у больных с термической травмой. Регионарное кровообращение и микроциркуляция. 2013; 2 (46): 43-8.

13. Iba T, Kidokoro A, Fukunaga M, et al. Association between the severity of sepsis and the changes in hemostatic molecular markers and vascular endothelial damage markers. Shock. 2005; 23 (1): $25-9$.

14. Фирсов С. А., Матвеев Р. П. Эндотелиальная диссункция и ее прогностическое значение при критических состояниях в результате дорожно-транспортного травматизма. Современные проблемы науки и образования. 2014; 6. Доступно по ссылке: http://science-education.ru/ru/article/view?id=16629 (дата обращения: 24.03.2019).

15. Scharpfenecker $M$, Fiedler $U$, Reiss $Y$, Augustin HG. The Tie-2 ligandangiopoietin-2 destabilizes quiescent endothelium through an internal autocrine loop mechanism. J Cell Sci. 2005; 118 (4): $771-80$.

16. Abo El-Noor MM, Elgazzar FM, Alshenawy HA. Role of inducible nitric oxide synthase and interleukin- 6 expression in estimation of skin burn age and vitality. J Forensic Leg Med. 2017; (52): 148-53.

\section{References}

1. Dumnicka P, Maduzia D, Ceranowicz P, et al. The Interplay between Inflammation, Coagulation and Endothelial Injury in the Early Phase of Acute Pancreatitis: Clinical Implications. Int J Mol Sci. 2017; 18 (2): E354. DOI: 10.3390/ijms18020354. PubMed PMID: 28208708.

2. Alekseev AA, Ushakova TA, Krutikov MG, Bobrovnikov AYe. Markery sepsisa v diagnostike adaptivnogo vospalenija pri ozhogovoj travme. Lechenie i profilaktika. 2015; 2 (14): 84-91. Russian.

3. Ushakova TA. Adaptacija k ozhogovoj travme: problemy perspektivy. Kombustiologija. 2009; 39. Dostupno po ssylke: www.combustiolog.ru (data obrashhenija 23.06.2018). Russian.

4. Chousterman BG, Swirski FK, Weber GF. Cytokine storm and sepsis disease pathogenesis. Semin Immunopathol. 2017; 39 (5): 517-28.

5. Ince C, Mayeux PR, Nguyen T, et al. The endothelium in sepsis. Shock. 2016; 45 (3): 259-70.

6. Abdel-Hafez NM, Saleh Hassan Y, El-Metwally TH. A study on biomarkers, cytokines, and growth factors in children with burn injuries. Ann Burns Fire Disasters. 2007; 20 (2): 89-100.

7. Petrishhev NN, Berkovich OA, Vlasov TD i dr. Diagnosticheskaja cennost' opredelenija deskvamirovannyh jendotelial'nyh kletok v krovi. Klinicheskaja laboratornaja diagnostika. 2001; (1): 50-2. Russian.

8. Gavrilenko TI, Ryzhkova NA, Parhomenko AN. Sosudistyj jendotelial'nyj faktor rosta $\vee$ klinike vnutrennih zabolevanij i ego patogeneticheskoe znachenie. Ukraïns'kij kardiologichnij zhurnal. 2011; (4): 87-95. Russian.

9. Erdbruegger U, Haubitez M, Woywodt A. Circulating endothelial

cells: a novel marker of endothelial damage. Clinica Chimica Acta. 2006; (373): 17-26.

10. Dremina NN, Shurygin MG, Shurygina IA. Jendoteliny v norme i patologii. Mezhdunarodnyj zhurnal prikladnyh i fundamental'nyh issledovanii. 2016; (10): 210-14. Russian.

11. Yanagisawa M, Masaki T. Molecular biology and biochemistry of the endothelins. Trends Pharmacol Sci. 1989; 10 (9): 374-8.

12. Morrison VV, Bozhedomov AYu. Disfunkcija jendotelija pri sindrome poliorgannoj nedostatochnosti u bol'nyh s termicheskoj travmoj. Regionarnoe krovoobrashhenie i mikrocirkuljacija. 2013; 2 (46): 43-8. Russian.

13. Iba T, Kidokoro A, Fukunaga $\mathrm{M}$, et al. Association between the severity of sepsis and the changes in hemostatic molecular markers and vascular endothelial damage markers. Shock. 2005; 23 (1): 25-9.

14. Firsov SA, Matveev RP. Jendotelial'naja disfunkcija i ee prognosticheskoe znachenie pri kriticheskih sostojanijah $v$ rezul'tate dorozhno-transportnogo travmatizma. Sovremennye problemy nauki i obrazovanija. 2014; 6. Dostupno po ssylke: http://science-education.ru/ru/article/view?id=16629 (data obrashhenija: 24.03.2019). Russian.

15. Scharpfenecker M, Fiedler U, Reiss Y, Augustin HG. The Tie-2 ligandangiopoietin-2 destabilizes quiescent endothelium through an internal autocrine loop mechanism. J Cell Sci. 2005; 118 (4): 771-80.

16. Abo El-Noor MM, Elgazzar FM, Alshenawy HA. Role of inducible nitric oxide synthase and interleukin- 6 expression in estimation of skin burn age and vitality. J Forensic Leg Med. 2017; (52): 148-53. 